\title{
Anaerobic Digestion of Hemicellulosic Sugars Implemented in ADM1
}

\author{
Vibeke Bredvold Karlsen Nirmal Ghimire Rune Bakke Wenche Hennie Bergland \\ Department of Process, Energy and Environmental Technology, University of South-Eastern Norway \\ Vibeke.B.Karlsen@usn.no, Nirmal.Ghimire@usn.no, Rune.Bakke@usn.no, Wenche.Bergland@us \\ $\underline{\text { n. no }}$
}

\begin{abstract}
Lignocellulosic biomass is a sustainable and renewable source for both solids like biochar and biomethane by anaerobic digestion (AD). Hot water extraction (HWE) improves the total utilization of the biomass and produces a hydrolysate rich in hemicellulosic sugars with characteristics that needs to be understood. A study of the AD process in batch reactors with synthetic substrates composed of hemicellulosic sugars was performed and modelled using the standard IWA Anaerobic Digestion Model No. 1 (ADM1). Simulations were also performed using three strategies: 1) varying the stoichiometry for monosaccharide degradation, 2) varying the maximum uptake rate of the monosaccharide degrading organisms and 3) including a first order rate limiting step. The ADM1 model is a good tool but gave initially moderate agreement with the experimental results. The first two strategies did not improve the simulations but it improved significantly upon incorporating a rate limiting step, thereby simulating possible effects based on types of microorganisms present and diffusion limitations.
\end{abstract}

Keywords: anaerobic digestion, lignocellulosic hydrolysate, hemicellulosic sugars, ADM1, first order step

\section{Introduction}

Renewable materials can replace fossil materials as a source for energy and to produce new and existing products. This has shifted the focus to renewable material sources. Lignocellulosic biomass, such as woody biomass, agricultural and forest residues, energy crops and grasses, is a large potential source of new materials and renewable energy. Treatments such as hot water extraction and steam explosion, commonly used on lignocellulosic biomass to remove volatiles before renewable solid material production, extract hemicellulose from the lignocellulosic biomass. The hemicellulose shows promising results as a degradable material in anaerobic digestion for biogas production, whereas untreated lignocellulosic biomass has low biodegradability (Hu and Ragauskas, 2012) due to the main components cellulose (38-50\%), hemicellulose (23-32\%) and lignin (10-25\%) being linked together and packed closely. Through hydrolysis of hemicellulose during hot water treatment, easily degradable pentose (xylose and arabinose) and hexose sugars (glucose, mannose and galactose) are produced along with acetic acid (Amidon and Liu, 2009).

The concentration of sugars varies in lignocellulosic biomass. Softwoods, like spruce and pine, contain more mannose and glucose in comparison with the other sugars while hardwoods, like aspen, oak and willow, contain a higher amount of xylose (Palmqvist and HahnHaagerdal, 2000).

The Anaerobic Digestion Model No.1 (ADM1) (Batstone et al., 2002a) has been applied for different AD systems and its performances studied for various substrates and reactor configurations (Gehring et al., 2013). The ADM1 model is developed to handle sludge with complex materials consisting of fat, protein and carbohydrates. However, simulation of AD of individual hemicellulosic sugars found in lignocellulosic biomass in ADM1 is still rare and needs to be studied carefully to understand underlying mechanisms to increase the biodegradability. Processes related to carbohydrates are important for lignocellulosic biomass.

The aim of this paper is to evaluate ADM1 as a tool for simulating $\mathrm{AD}$ of sugars typically found in hydrolysates prepared by hot water extraction of lignocellulosic biomass. Kinetic parameters were estimated based on batch experiments for each of the sugars which were made synthetically. Moreover, simulations were performed with variations in the stoichiometry during VFA production from monosaccharides and the soluble sugar degrading kinetic values and compared with the experimental results.

\section{Materials and Methods}

Major hemicellulosic sugars present in hydrolysate of lignocellulosic substrates, but made synthetically here, are tested in anaerobic batch reactors and modelled in ADM1 individually. 


\subsection{Material Characterization}

\subsubsection{Substrate}

Five different synthetic substrates were prepared from powder of one of the hemicellulosic sugars glucose, mannose, arabinose, galactose and xylose (Table 1). The D-form of all the sugars were used in the experiments. The D-form of the sugars are most common in nature, except for arabinose most commonly present in L-form (McMurry, 2014).

Table 1. Sugars used to produce the synthetic substrates

\begin{tabular}{|l|l|}
\hline Sugar(Sigma-Aldrich) & Mass percentage of sugar \\
\hline D-Glucose & $\geq 99.5 \%$ \\
\hline D-Mannose & $\geq 99 \%$ \\
\hline D-Xylose & $\geq 99 \%$ \\
\hline D-Arabinose & $\geq 98 \%$ \\
\hline D-Galactose & $\geq 99 \%$ \\
\hline
\end{tabular}

Each sample was prepared by diluting 1 gram of the respective sugar with $100 \mathrm{~mL}$ of distilled water to a sugar concentration of $10 \mathrm{~g} \mathrm{~L}^{-1}$. Macronutrients (Table 2) and micronutrients (Table 3 ) were added to provide required nutrients with a COD: $\mathrm{N}$ : $\mathrm{P}$ ratio of 350:5:1 (Baeta et al., 2013). $\mathrm{NaOH}$ was added to increase the $\mathrm{pH}$ to a range of 7-7.5.

Table 2. Composition and concentration of macronutrients

\begin{tabular}{|l|l|}
\hline Macronutrients \\
\hline Type of chemical & Concentration $\left(g L^{-1}\right)$ \\
\hline $\mathrm{NH}_{4} \mathrm{Cl}$ & 44.48 \\
\hline$\left(\mathrm{NH}_{4}\right) \mathrm{H}_{2} \mathrm{PO}_{4}$ & 5.3 \\
\hline$\left(\mathrm{NH}_{4}\right)_{2} \mathrm{HPO}_{4}$ & 1.78 \\
\hline $\mathrm{MgCl}_{2} \cdot 6 \mathrm{H}_{2} \mathrm{O}$ & 21.4 \\
\hline $\mathrm{CaCl}_{2} \cdot 2 \mathrm{H}_{2} \mathrm{O}$ & 7.56 \\
\hline $\mathrm{NaHCO}_{3}$ & 100 \\
\hline
\end{tabular}

Table 3. Composition and concentration of micronutrients

\begin{tabular}{|c|c|}
\hline \multicolumn{2}{|l|}{ Micronutrients } \\
\hline Type of chemical & Concentration $\left(g L^{-1}\right)$ \\
\hline Yeast Extract & 2.5 \\
\hline $\mathrm{FeCl}_{3} \cdot 6 \mathrm{H}_{2} \mathrm{O}$ & 0.2 \\
\hline $\mathrm{ZnCl}_{2}$ & 5.2 \\
\hline $\mathrm{MnCl}_{2} \cdot 4 \mathrm{H}_{2} \mathrm{O}$ & 0.047 \\
\hline$\left(\mathrm{NH}_{4}\right)_{6} \mathrm{Mo}_{7} \mathrm{O}_{24} \cdot 4 \mathrm{H}_{2} \mathrm{O}$ & 0.064 \\
\hline $\mathrm{AlKO}_{8} \mathrm{~S}_{2} \cdot 12 \mathrm{H}_{2} \mathrm{O}$ & 0.01 \\
\hline $\mathrm{CoCl}_{2} \cdot 6 \mathrm{H}_{2} \mathrm{O}$ & 0.2 \\
\hline $\mathrm{NiCl}_{2} \cdot 6 \mathrm{H}_{2} \mathrm{O}$ & 0.52 \\
\hline $\mathrm{H}_{3} \mathrm{BO}_{3}$ & 0.12 \\
\hline $\mathrm{CuCl}_{2} 2 \mathrm{H}_{2} \mathrm{O}$ & 0.32 \\
\hline $\mathrm{HCl}$ & 20 \\
\hline
\end{tabular}

\subsubsection{Inoculum}

The inoculum used was granular sludge (Table 4) obtained from a mesophilic industrial internal recirculation reactor treating paper mill effluent.

Table 4. Properties of granular sludge

\begin{tabular}{|l|l|}
\hline Parameters & Values \\
\hline Density $\left(\mathrm{kg} \mathrm{m}^{-3}\right)$ & $1.00-1.09$ \\
\hline Diameter $(\mathrm{mm})$ & $0.6-2.7$ \\
\hline Settling velocity $\left(\mathrm{m} \mathrm{h}^{-1}\right)$ & $68-71$ \\
\hline Total Solids $\left(\mathrm{g} \mathrm{L}^{-1}\right)$ & 181 \\
\hline Volatile Solids $\left(\mathrm{g} \mathrm{L}^{-1}\right)$ & 119 \\
\hline $\mathrm{pH}$ & 7.46 \\
\hline
\end{tabular}

\subsection{Batch Reactors Set up}

$100 \mathrm{~mL}$ syringes were used as batch reactors in accordance with Ostgaard et al. (2017). Five parallel batch reactors were prepared for each sugar and fed with $15 \mathrm{~mL}$ inoculum and $14.1 \mathrm{~mL}$ substrate to have a uniform organic load of 10 gCOD L L $^{-1} .3$ blank parallel reactors containing only inoculum and distilled water were also prepared to correct for biogas generated from the inoculum. All the reactors were run at $35^{\circ} \mathrm{C}$ for 19 days.

\subsection{Analytical Methods}

Biogas production was measured manually in accordance with Ostgaard et al. (2017), and gas composition was measured when the volume was higher than $5 \mathrm{~mL}$ by gas chromatography (SRI 8610-C) as described by Bergland et al. (2015). Liquid phase COD (total and soluble), volatile fatty acids (VFAs), including acetate, propionate, butyrate, iso-butyrate, valerate, iso-valerate, iso-caprionate, caprionate and heptanate, $\mathrm{pH}$ and ammonium content $\left(\mathrm{NH}_{4}^{+}\right)$were sampled and measured as described in Bergland et al. (2015).

\subsection{Modelling and Simulation Methods}

Simulations of batch tests were performed using the Anaerobic Digestion Model No. 1 (ADM1) in Aquasim. The ADM1 was applied to model the processes with stoichiometric coefficients, equilibrium coefficients, dynamic states and algebraic variables as proposed by Batstone et al. (2002b), for all biochemical and physiochemical processes.

The following strategies were used to simulate batch reactors with hemicellulosic sugars in ADM1:

- Using kinetic and stoichiometric parameters as proposed by Batstone et al. (2002a).

- Varying the stoichiometry during VFA production from monosaccharides, affecting the acetate (fac,su), butyrate (fbu,su) and propionate (fpro,su) obtained through monosaccharide degradation.

- Varying the maximum uptake rate of the monosaccharide degrading organisms (km,su). 
- Adding the sugars as carbohydrates, thereby including a first order step.

In all the simulations, the reactor volume was set to $29.1 \mathrm{~mL}$ and the temperature to $35^{\circ} \mathrm{C}$ in accordance with the batch experiments.

\subsubsection{Substrate characteristics}

Substrate concentrations implemented (Table 5) were calculated based on the substrate characteristics. Since the substrates only contained sugars (sCOD), the amount of sugar was added as $\mathrm{S}_{\mathrm{su}}$. In ADM1 the hexose glucose is used as a model monomer. Pentoses have similar yields as the hexoses, but obtain one less $\mathrm{CO}_{2}$ or carboxylic acid (Batstone et al., 2002a). All the individual sugars were therefore included as $S_{\text {su }}$ without modifying the stoichiometry of the sugars, and the batch reactors were added equal amounts of sCOD. The parameters related to particulates $\left(\mathrm{X}_{\mathrm{c}}, \mathrm{X}_{\mathrm{ch}}\right.$ and $\left.\mathrm{X}_{\mathrm{I}}\right)$ were set to zero in the simulations.

Table 5. Concentrations of hemicellulosic sugars in the substrates

\begin{tabular}{|l|l|l|}
\hline Parameters & Description & $\begin{array}{l}\text { Values used in the } \\
\text { simulations }\end{array}$ \\
\hline $\mathrm{S}_{\mathrm{su}}$ & Monosaccharides & $5.136 \mathrm{kgCOD} \mathrm{m}^{-3}$ \\
\hline $\mathrm{S}_{\mathrm{I}}$ & Soluble inerts & $0.36 \mathrm{kgCOD} \mathrm{m}^{-3}$ \\
\hline $\mathrm{S}_{\mathrm{IN}}$ & $\begin{array}{l}\text { Inorganic } \\
\text { nitrogen }\end{array}$ & $0.0092 \mathrm{M}$ \\
\hline
\end{tabular}

The $S_{\text {cat }}$ and $S_{\text {an- }}$ were adjusted in the simulations to tune the initial $\mathrm{pH}$ to fit the experiments. These parameters were adjusted because they only affect the $\mathrm{pH}$, but otherwise can be treated as inerts in the simulations (Batstone et al., 2002a).

\subsubsection{Stoichiometry of sugar degradation to VFA}

One important step in the anaerobic digestion of sugars is the acidogenesis of monosaccharides, and there are different acidogenic metabolic pathways in anaerobic digesters (Batstone et al., 2002a; Zhou et al., 2018). Which pathway that dominates, depends on the microorganisms, the substrate and the conditions in the reactor. The different pathways result in different ratios of the resulting VFAs.

In ADM1, reactions 1-3 describes the degradation of the glucose monomer to acetic acid, propionic acid and butyric acid.

1. Acetate: $\mathrm{C}_{6} \mathrm{H}_{12} \mathrm{O}_{6}+2 \mathrm{H}_{2} \mathrm{O} \rightarrow 2 \mathrm{CH}_{3} \mathrm{COOH}+2 \mathrm{CO}_{2}+$ $4 \mathrm{H}_{2}$

2. Acetate, propionate: $3 \mathrm{C}_{6} \mathrm{H}_{12} \mathrm{O}_{6} \rightarrow 4 \mathrm{CH}_{3} \mathrm{CH}_{2} \mathrm{COOH}$ $+2 \mathrm{CH}_{3} \mathrm{COOH}+2 \mathrm{CO}_{2}+2 \mathrm{H}_{2} \mathrm{O}$

3. Butyrate: $\mathrm{C}_{6} \mathrm{H}_{12} \mathrm{O}_{6} \rightarrow \mathrm{CH}_{3} \mathrm{CH}_{2} \mathrm{CH}_{2} \mathrm{COOH}+2 \mathrm{CO}_{2}+$ $2 \mathrm{H}_{2}$

According to Batstone et al. (2002a) the first is the most common reaction in $\mathrm{AD}$, followed by the second and third. This is graded in ADM1 by equations 4-7 giving the yields of acetic acid ( $\left.f_{a c, s u}\right)$, butyric acid ( $\left.f_{b u, s u}\right)$ and propionic acid ( $\left.\mathrm{f}_{\mathrm{pro}, \mathrm{su}}\right)$.

$$
\begin{aligned}
& \text { Acetate: } f_{a c, s u}=0.67 \cdot \eta_{1, s u}+0.22 \cdot \eta_{2, s u} \\
& \text { Propionate: } f_{\text {prossu }}=0.78 \cdot \eta_{2, s u} \\
& \text { Butyrate: } f_{b u, s u}=0.83 \cdot\left(1-\eta_{2, s u}-\eta_{1, s u}\right) \\
& \eta_{3, s u}=1-\eta_{2, s u}-\eta_{1, s u}
\end{aligned}
$$

$\eta_{1, \mathrm{su}}, \eta_{2, \mathrm{su}}$ and $\eta_{3, \mathrm{su}}$ are the fractions of sugars that degrades through the reactions 1-3.

The $\eta$-values were varied in simulations to study the effect of changing the fractions of the different VFAs (Table 6). This was done to alternate the dominating acidogenic pathway. In these simulations, the fraction of acetic acid is decreased, the fraction of butyric acid is increased and the fraction of propionic acid is mostly

\begin{tabular}{|c|c|c|c|c|}
\hline $\begin{array}{l}\text { Name of } \\
\text { curve }\end{array}$ & $\eta_{1, s u}$ & $\eta_{2, s u}$ & $\eta_{3, s u}$ & $\begin{array}{l}\text { Yields } \quad \text { of } \\
\text { VFAs }\end{array}$ \\
\hline \multirow{3}{*}{$\begin{array}{l}\text { (original) } \\
\text { ADM1 }\end{array}$} & \multirow[t]{3}{*}{0.495} & \multirow[t]{3}{*}{0.345} & \multirow[t]{3}{*}{0.16} & $\mathrm{f}_{\mathrm{ac}, \mathrm{su}}=0.41$ \\
\hline & & & & $f_{\text {pro,su }}=0.27$ \\
\hline & & & & $f_{b u, s u}=0.13$ \\
\hline \multirow[t]{3}{*}{ No_1 } & \multirow[t]{3}{*}{0.395} & \multirow[t]{3}{*}{0.245} & \multirow[t]{3}{*}{0.36} & $f_{a c, s u}=0.32$ \\
\hline & & & & $f_{\text {pro,su }}=0.19$ \\
\hline & & & & $f_{\mathrm{bu}, \mathrm{su}}=0.30$ \\
\hline \multirow[t]{3}{*}{ No_2 } & \multirow[t]{3}{*}{0.295} & \multirow[t]{3}{*}{0.245} & \multirow[t]{3}{*}{0.46} & $f_{a c, s u}=0.25$ \\
\hline & & & & $f_{\text {pro,su }}=0.19$ \\
\hline & & & & $f_{b u, s u}=0.38$ \\
\hline \multirow[t]{3}{*}{ No_3 } & \multirow[t]{3}{*}{0.195} & \multirow[t]{3}{*}{0.245} & \multirow[t]{3}{*}{0.56} & $\mathrm{f}_{\mathrm{ac}, \mathrm{su}}=0.18$ \\
\hline & & & & $f_{\text {pro,su }}=0.19$ \\
\hline & & & & $f_{\mathrm{bu}, \mathrm{su}}=0.46$ \\
\hline \multirow[t]{3}{*}{ No_4 } & \multirow[t]{3}{*}{0.095} & \multirow[t]{3}{*}{0.245} & \multirow[t]{3}{*}{0.66} & $f_{a c, s u}=0.12$ \\
\hline & & & & $f_{\text {pro,su }}=0.19$ \\
\hline & & & & $f_{b u, s u}=0.55$ \\
\hline \multirow[t]{3}{*}{ No_5 } & \multirow[t]{3}{*}{0.045} & \multirow[t]{3}{*}{0.195} & \multirow[t]{3}{*}{0.76} & $f_{a c, s u}=0.07$ \\
\hline & & & & $f_{\text {pro,su }}=0.15$ \\
\hline & & & & $f_{b u, s u}=0.63$ \\
\hline
\end{tabular}
kept constant but at a lower level than in the original model. All the other parameters were kept constant.

Table 6. Yields of VFA used in the simulations

\subsubsection{Uptake rate of monosaccharides}

The uptake of monosaccharides is described by Monod kinetics (8).

uptake $_{s u}=k m_{s u} \bullet X_{s u} \cdot \frac{s_{s u}}{s_{s u}+K s_{s u}} \bullet I_{p H_{b a c}} \bullet I_{N H_{\text {limit }}}$

where $\mathrm{km}_{\mathrm{su}}$ is the maximum uptake rate for monosaccharide degrading organisms, $\mathrm{S}_{\mathrm{su}}$ is the concentration of monosaccharides, $\mathrm{Ks}_{\mathrm{su}}$ is the half saturation constant for monosaccharide degradation, $\mathrm{X}_{\mathrm{su}}$ is the monosaccharide degrading organisms, $\mathrm{I}_{\mathrm{pH}_{\mathrm{bac}}}$ is the inhibition caused by $\mathrm{pH}$ on acidogens and acetogens and 
$\mathrm{I}_{\mathrm{NH}_{\text {limit }}}$ is the function to limit growth due to lack of inorganic nitrogen.

The parameter $\mathrm{km}_{\mathrm{su}}$ was evaluated in relation to the experiments performed with the hemicellulosic sugars. All the other parameters were kept constant throughout these simulations. The simulations were performed by changing the maximum uptake rate for the monosaccharide degrading organisms, $\mathrm{km}_{\text {su. }}$. A startingvalue of $30 \mathrm{gCOD} \mathrm{gCOD}^{-1} \mathrm{~d}^{-1}$, proposed by Batstone et al. (2002a), was used for the degradation of sugar, and the value was varied in the range of $15-50 \mathrm{gCOD} \mathrm{gCOD}^{-}$ ${ }^{1} \mathrm{~d}^{-1}$.

\subsubsection{First order step}

ADM1 is structured in several main steps including disintegration, hydrolysis, acidogenesis, acetogenesis and methanogenesis. The rate limiting step for dissolved substrates is most often methanogenesis, while it is hydrolysis for particulate substrates. Including a first order step is done by adding the substrate as carbohydrates that need to undergo extracellular hydrolysis to form simple monosaccharides that can be taken up by the bacteria. In ADM1, hydrolysis of carbohydrates $X_{\mathrm{ch}}$ is already implemented with a simple first order rate expression (9) producing monosaccharides, $\mathbf{S}_{\mathrm{su}}$.

$$
\rho=k_{\text {hyd_ch }} \cdot X_{c h}
$$

where $\rho$ is the hydrolysis rate of solid substrates $(\mathrm{kg}$ COD solid substrate $\left.\mathrm{m}^{-3} \mathrm{~d}^{-1}\right), \mathrm{X}_{\mathrm{ch}}$ is the particulate carbohydrate concentration ( $\mathrm{kg}$ COD solid substrate $\mathrm{m}^{-}$ $\left.{ }^{3}\right)$ and $\mathrm{k}_{\text {hyd_ch }}$ is the kinetic parameter for hydrolysis $\left(\mathrm{d}^{-}\right.$ ${ }^{1}$ ). The hydrolysis constants, khyd_ch, (here not necessary representing hydrolysis), were estimated individually for each substrate using the parameter estimation function in Aquasim.

\section{Results and Discussion}

\subsection{Experimental results}

The biogas production from the five hemicellulosic sugars (Figure 1) had some variance in both the biogas production rate and methane yield. The biogas production from glucose and mannose started within a few hours, whereas a short lag-phase was observed for xylose, galactose and arabinose. The biogas production rate from arabinose were noticeable slower compared to the other sugars. The methane yields calculated (Figure 1) were in the range of 0.74-0.9 $\left(\mathrm{gCOD}_{\mathrm{CH}} 4 / \mathrm{gCOD}_{\text {Substrate }}\right)$, where glucose reached the highest yield and arabinose the lowest yield.

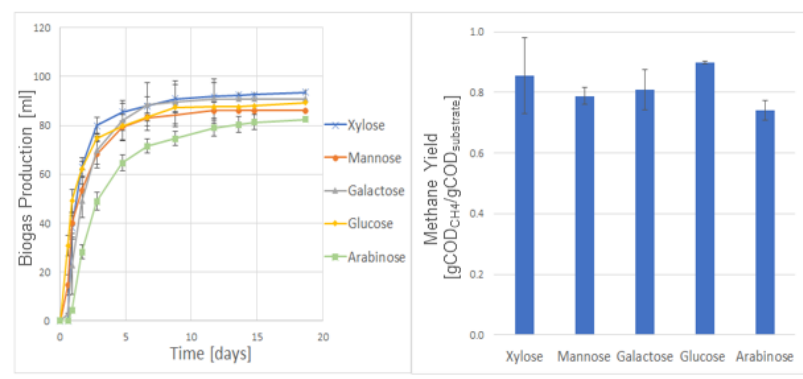

Figure 1. Experimental results from batch tests with hemicellulosic sugars. Left: Accumulated biogas production, Right: Methane yields

$\left[\mathrm{gCOD}_{\mathrm{CH}} / \mathrm{gCOD}_{\text {Substrate }}\right]$

\subsection{Simulations}

The simulation results obtained with ADM1 in Aquasim were compared to the experimental results from the five hemicellulosic sugars.

\subsubsection{Variation of the monosaccharide degradation stoichiometry}

Changing the stoichiometry for monosaccharide degradation producing VFA had low impact within the variations tested.

At a load of $10 \mathrm{kgCOD} \mathrm{m}^{-3}$ used for the hemicellulosic sugars both in the experiments and the simulations, the VFA accumulation was low and the degradation of the VFAs fast, not influencing the biogas production rate or the $\mathrm{pH}$ (Figure 2). At higher load, this mechanism might be of higher importance due to possible VFA accumulation and the difference in the degradation rate of the VFAs (Batstone et al., 2002a).

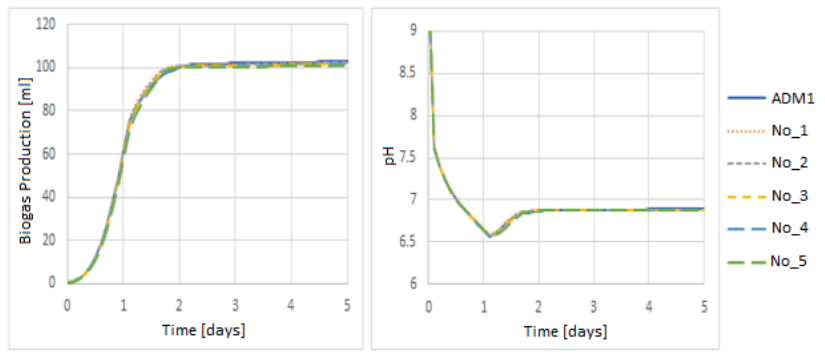

Figure 2. Simulation results with varying fractions of the VFAs (named ADM1 to No_5, Table 6). Left:

Accumulated biogas production, Right: $\mathrm{pH}$

\subsubsection{Variations of the monosaccharide degradation kinetics}

The simulation results indicate that the $\mathrm{km}$-value has a clear impact on the initial biogas production (Figure 3). An increase in the $\mathrm{km}$-value increases the uptake rate of monosaccharides, increase the concentration of VFAs and reduce the $\mathrm{pH}$ (Figure 3). Initially, the gas production is higher with the highest $\mathrm{km}$-values because of the higher uptake rates of the organisms. The fit with experimental values, taking mannose as a model substrate, did not improve by changing the $\mathrm{km}$-values 
from 15 to 50 . The total biogas produced reaches the same level independently of the $\mathrm{km}$-value (rate).

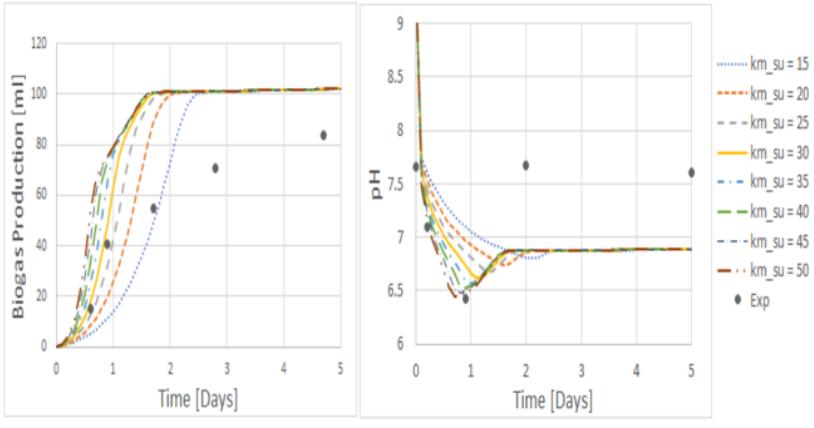

Figure 3. Simulation results with changes in the kmvalue. Experimental values are from mannose. Left: Accumulated biogas production, Right: $\mathrm{pH}$

\subsubsection{Simulations with addition of a first order step}

The simulations adding the sugars as monosaccharides, without the first order step, gave only moderate fit with the experimental results (Figure 4) due to fast degradation of sCOD, and the experimentally observed lag-phases were not seen in the simulations, with the largest difference for arabinose.

Including the concentration dependent first order rate expression clearly improved the fit between simulated and experimental biogas production (Figure 4). The largest improvements were obtained for the sugars with an observed lag-phase during the experiments (arabinose, galactose and xylose). Glucose, the model monomer used in ADM1, obtained the lowest improvement of the five sugars, but still improved noticeably.

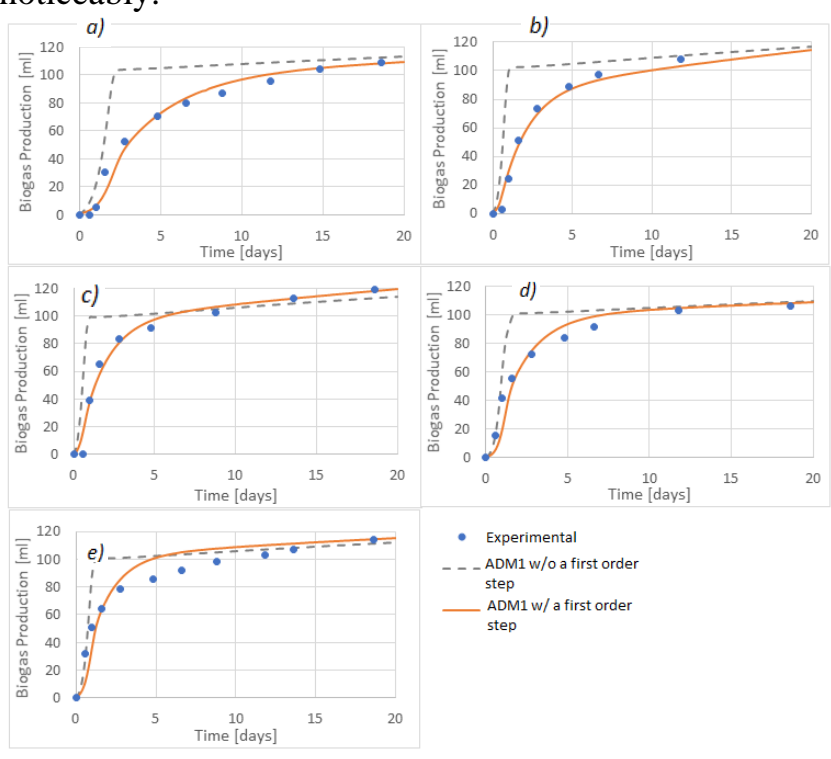

Figure 4. Simulated accumulated biogas production without a first order step (dashed line), with an added first order step (solid line) and experimental for a) Arabinose, b) Galactose, c) Xylose, d) Mannose and e) Glucose

The individual first order constants are estimated with parameter estimation in Aquasim (Table 7). The experimentally measured sCOD and the simulated substrate COD show the same trends in degradation, which indicates a resembling degradation rate (results not included here).

Table 7. Estimated first order constants

\begin{tabular}{|l|l|}
\hline Sugar & $\begin{array}{l}\text { Estimated first order } \\
\text { constant }\left[d^{-1}\right]\end{array}$ \\
\hline Glucose & 0.64 \\
\hline Mannose & 0.52 \\
\hline Xylose & 0.61 \\
\hline Galactose & 1 \\
\hline Arabinose & 0.27 \\
\hline
\end{tabular}

It is not obvious from the sugar chemistry that the carbohydrates used as substrate here need to undergo hydrolysis to be taken up by the acid forming bacteria. However, the simulation results clearly suggest that including the hydrolysis step in ADM1 in the form of a concentration dependent first order rate expression improves the simulations. Due to the simplicity and universality of this step, there are different processes related to sugar degradation that should be considered in this perspective. The uptake and degradation processes by the different monosaccharides could be more complex than included in ADM1. In addition, the types of microorganisms present could be important. Certain microorganisms mainly digest hexoses, while others digest both hexoses and pentoses (Chandrakant and Bisaria, 1998; Larsson, 1999). The ratio between these and the adaption period can be important regarding the sugar degradation rate. Hence, knowledge of the available microorganisms is important to modify ADM1 by distinguishing between the microorganisms as proposed by Ramirez et al. (2009).

Another consideration is the difference in degradation of sCOD in the reactors. Experimentally, the biogas production slows down as the SCOD in the batch reactor decreases. In the simulations, the biogas production continues at the same rate until the sugar is completely degraded. This difference might be caused by diffusion and lower accessibility of substrate for the microorganisms as the concentration of available substrate is lower. The simulations account for the decrease in substrate concentration with time, but the lower accessibility is not accounted for.

It is difficult to determine the exact process or the sum of processes that evidently makes it appropriate to include the first order rate expression. Of this reason, it is concluded that a step corresponding to the hydrolysis step in ADM1 could be included to model these reactions since it can be the rate limiting step. Further studies of the uptake and degradation kinetics of simple sugars are suggested to elucidate the underlying mechanisms. 


\section{Conclusion}

The ADM1 model is a good tool to predict the biogas production from the hemicellulosic sugars during AD. The simulation results show moderate to good agreement with the experimental results depending on some key parameters. Adjusting the maximum substrate uptake rate of monosaccharides $\left(\mathrm{km}_{\mathrm{su}}\right)$ and the stoichiometry during monosaccharide degradation to the VFAs acetic acid, propionic acid and butyric acid (by varying $\eta_{1, \mathrm{su}}, \eta_{2 \text {,su }}$ and $\eta_{3 \text {,su }}$ ) had little influence on simulation fits to experimental results. The first order reaction step, usually accounting for hydrolysis, improved the fit between simulations and experimental biogas production from the hemicellulosic sugars, including the observed lag-phases. It is argued that the underlying mechanism, however, is not hydrolysis but rather related to type of microorganism and diffusion limitations.

\section{Acknowledgements}

The project was supported by the Pyrogas Project funded by The Norwegian Research Council and the University of South-Eastern Norway. The authors wish to thank Jitendra Sah and Zahra Nikbakht Kenarsari for the good cooperation in carrying out the experiments.

\section{References}

T.E. Amidon and S. Liu. Water-based woody biorefinery. Biotechnology Advances, 27(5): 542-550, 2009. https://doi.org/10.1016/j.biotechadv.2009.04.012

B.E. Baeta, H.J. Luna, A.L. Sanson, S.Q. Silva, and S.F. Aquino. Degradation of a model azo dye in submerged anaerobic membrane bioreactor (SAMBR) operated with powdered activated carbon (PAC). Journal of Environmental Management, 128 : 462-470, 2013. https://doi.org/10.1016/ j.jenvman.2013.05.038

D.J. Batstone, J. Keller, I. Angelidaki, S.V. Kalyuzhny, S.G. Pavlostathis, A. Rozzi, W.T.M. Sanders, H. Siegrist, and V.A. Vavilin. Anaerobic digestion model No. 1 (ADM1), IWA Publishing, London, UK, 2002a.

D.J. Batstone, J. Keller, I. Angelidaki, S. Kalyuzhnyi, S. Pavlostathis, A. Rozzi, W. Sanders, H. Siegrist, and V. Vavilin. The IWA anaerobic digestion model no 1 (ADM1). Water Science and Technology, 45(10): 65-73, 2002b. https://doi.org/10.2166/wst.2002.0292

W.H. Bergland, C. Dinamarca, M. Toradzadegan, A.S. Nordgard, I. Bakke, and R. Bakke. High rate manure supernatant digestion. Water Research, 76, 1-9, 2015. https://doi.org/10.1016/j.watres.2015.02.051

P. Chandrakant and V.S. Bisaria. Simultaneous Bioconversion of Cellulose and Hemicellulose to ethanol. Critical Reviews in Biotechnology, 18(4): 295-331, 1998. https://doi.org/10.1080/0738-859891224185

T. Gehring, M. Lübken, K. Koch, and M. Wichern. ADM1 simulation of the thermophilic mono-fermentation of maize silage-Use of an uncertainty analysis for substrate characterization, $13^{\text {th }}$ World Congress on Anaerobic Digestion, 28, 2013.
F. Hu and A. Ragauskas. Pretreatment and Lignocellulosic Chemistry. BioEnergy Research, 5(4): 1043-1066, 2012. https://doi.org/10.1007/s12155-012-9208-0

S. Larsson, E. Palmqvist, B. Hahn-Hägerdahl, C. Tengborg, K. Stenberg, G. Zacchi, and N.-O. Nilvebrant. The generation of fermentation inhibitors during dilute acid hydrolysis of softwood. Enzyme and Microbial Technology, 24: 151-159, 1999. https://doi.org/10.1016/S01410229(98)00101-X

J.E. McMurry. Organic Chemistry with Biological Applications. Cengage Learning, 2014.

K. Ostgaard, V. Kowarz, W. Shuai, I.A. Henry, M. Sposob, H.H. Haugen, and R. Bakke. Syringe test screening of microbial gas production activity: Cases denitrification and biogas formation. Journal of Microbiology Methods, 132: 119-124, 2017. https://doi.org/10.1016/ j.mimet.2016.11.021

E. Palmqvist and B. Hahn-Haagerdal. Fermentation of lignocellulosic hydrolysates II inhibitors and mechanisms of inhibition. Bioresource Technology, 74: 25-33, 2000. https://doi.org/10.1016/S0960-8524(99)00161-3

I. Ramirez, E.I.P. Volcke, R. Rajinikanth, and J.P. Steyer. Modelling microbial diversity in anaerobic digestion through extended ADM1 model. Water Research, 43: 2787-2800, 2009. https://doi.org/10.1016/ j.watres.2009.03.034

M. Zhou, B. Yan, J.W.C. Wong, J. W. C. and Y. Zhang. Enhanced volatile fatty acids production from anaerobic fermentation of food waste: A mini-review focusing on acidogenic metabolic pathways. Bioresource Technology, 248: 6878, 2018. https://doi.org/10.1016/j.biortech.2017.06.121 